\title{
Genotype $\times$ Environment Interaction and Yield Stability of Large Speckled Common Bean (Phaseolus vulgaris L.) Genotypes in Ethiopia Using AMMI Analysis
}

\author{
Meseret Tola*, Adane Arega, Chala Debela, Solomon Bekele, Alemayehu Dhabessa \\ Bako Agricultural Research Center/Oromia Agricultural Research Institute \\ P.O.box 03, Bako, Oromia, Ethiopia
}

\begin{abstract}
Common beans are grown throughout Ethiopia and an increasingly important commodity in the cropping systems of smallholder producers both for food security and income. However, happening of significant genotype X environment interaction (GEI) complicates selection of stable genotypes. Nowadays, the yield potential of common bean is underutilized due to inadequate addressing of all potential areas and mismatch between selection and production environments. Thus, 17 large speckled common bean genotypes were evaluated at three locations (Bako, Billo and Gute) for two consecutive years to estimate the magnitude of GEI effects and to identify broadly or specifically adapted genotypes during 2015 and 2016 main cropping seasons. The genotypes were arranged in Randomized complete block design with three replications. Combined ANOVA, AMMI and GGE biplot models were used to analyze the data. Both main and interaction effects were highly significant $(\mathrm{P}<0.01)$ and environment, genotype, and GEI explained $49.8 \%, 25.1 \%$ and $20.0 \%$ variations, respectively, indicating greater influence of test environments and importance of simultaneous consideration of mean performance and stability. IPCA1 and IPCA2 were highly significant $(p<0.01)$ and together contributed more than $89.5 \%$ variation in the GEI sum of squares. AMMI 1 biplot enabled identification of broadly adapted genotypes, $\mathrm{G}_{3}$ (DAB-443) and $\mathrm{G}_{10}$ (DAB-364). GGE biplot analysis suggested presence of one megaenvironment and enabled identification of high seed yielding and broadly adapted genotypes (DAB-449 (G4)).
\end{abstract}

DOI: $10.7176 / \mathrm{JNSR} / 12-9-03$

Publication date:May $31^{\text {st }} 2021$

\section{Introduction}

Common bean (Phaseolus vulgaris L.) is the most important grain legume in nearly all lowland and mid-altitude areas of Ethiopia. It is produced primarily by smallholder farmers both for cash and consumption. According to CSA (2016), report red haricot bean was cultivated on 244,049.94 hectare of land and 3,804,994.5 Qt was produced with the productivity of 1.5 ton $\mathrm{ha}^{-1}$. In the study zone, the area covered by the crop during 2016 cropping season was $39,469.11$ ha and 59788.954 tons was produced with the productivity of 1.51 tons ha $^{-1}$. Its fastest ripening at the critical food deficit period earlier than other crops made it an ideal food deficit filler crop. It's suitability for double or triple production per year enabled its production on offseason free lands and relatively cheaper labor force. Its reasonable protein content $(22 \%)$ made it the poor man's meat securing more than 16.7 million rural people against hidden hunger (Zeleke et al., 2016).

In Ethiopia, it is grown suitably in areas with an altitude ranging between $1200-2200 \mathrm{~m}$ above sea level with optimum temperature range of $16-28^{\circ} \mathrm{C}$ and a rainfall of $350-500 \mathrm{~mm}$ well distributed over the growing season (Mekbib, 2003). It performs best on deep, friable and well aerated soil with good drainage, reasonably high nutrient content and $\mathrm{pH}$ range of 5.8 to 6.5. Particularly, in western Ethiopia common bean is one of the most important cash crops and source of protein for farmers in many lowlands and mid-altitude zones. Apart from being food and a source of income, common bean is also replenishes of soil fertility through biological nitrogen fixation.

When genotypes are introduced into new environments, genotype $\mathrm{x}$ environment interaction (GEI) is expected and in its presence, selection of superior genotypes based on means averaged over locations is misleading (Ebdon and Gauch, 2002b; Gauch and Zobel, 1997). GEI reflects differences in adaptation and can be exploited by selecting for specific adaptation or minimized by selecting for broad adaptation (Adjei et al., 2010). These objectives can be achieved by grouping environments into mega-environments and then selecting specifically adapted genotypes for each mega-environment or broadly adapted genotypes for wider environments (Zeleke et al, 2016). Multi-location evaluation of genotypes and stability analysis provides useful information for mega-environment classification and identification of broadly or specifically adapted genotypes (Crossa, 1990). Several statistical analysis methods have been used for interpretation of GEI. But currently, AMMI and GGE models are preferred tools for multi-location trials data analysis and which genotype outsmart where pattern discovery (Samonte et al., 2005; Yan et al., 2007; Asfaw et al., 2009; Namaratu et al., 2009). In western Oromia, there is no or little information on Genotype x Environment interaction and adaptability for large speckeled common bean genotypes. As a result, this study was done to estimate the magnitude of genotype by 
environment interaction effects and to analyse the stability of genotypes for seed yield performance in western low lands of Oromia.

\section{Materials and Methods}

Seventeen large speckled common bean genotypes including one standard check were evaluated under rain-fed conditions for two consecutive years (2015-2016) at Bako, Gute and Bilo boshe. The latitudes, longitudes, minimum and maximum temperature, soil type and total annual rain fall for each environment are presented in table 1. The experimental land was ploughed, disked and harrowed by tractor. The planting was done in midjune across all locations and Randomized complete bock design with three replication was used. Each plot consists six rows of four meter length with spacing of $40 \mathrm{~cm}$ between rows and $10 \mathrm{~cm}$ between plants. In organic fertilizer in the form of DAP $\left(18 \% \mathrm{~N}\right.$ and $\left.46 \% \mathrm{P}_{2} \mathrm{O}_{5}\right)$ was applied at the rate of $100 \mathrm{~kg}^{\mathrm{DAP}} \mathrm{ha}^{-1}$ during planting time. All other management practices were done as per the recommendations.

Multivariate method, Additive Main Effects and Multiplicative Interaction (AMMI) model was used to assess genotype by environment interaction (GEI) pattern. AMMI model is expressed as:

\section{$\boldsymbol{Y}_{i j}=\boldsymbol{\mu}+\boldsymbol{G i}+\boldsymbol{E j}+\left(\sum \lambda_{k} \boldsymbol{\alpha}_{i k} \gamma_{j k}\right)+\boldsymbol{P}_{i j}+\boldsymbol{e}_{i j}$}

Where $Y_{i j l}$ is the yield of genotype $(\mathrm{G})$ in environment $(\mathrm{E})$ for replicate $(\mathrm{r}), \mu$ is the total yield mean, $G_{i}$ is the main effect of genotype or the genotype $(\mathrm{G})$ mean deviation (genotype mean minus total yield mean), $E_{j}$ is the main effect of environment or the environment (E) mean deviation, $\lambda_{k}$ is the singular value for IPCA axis N ( $\mathrm{N}$ is the number of remain PCA axis in AMMI model: $\alpha_{i k}$ is the genotype (G) eigenvector value for IPCA axis $\mathrm{N}$, $\gamma_{j k}$ environment (E) eigenvector value for IPCA axis, $P_{i j}$ is the is the residual or noise and $+e_{i j l}$ is the error (Gauch, 1992; M. Umma Kulsum et al, 2014).

AMMI stability value of the $i^{\text {th }}$ genotype (ASV) was calculated for each genotype and each environment according to the relative contribution of IPCA 1 to IPCA 2 to the interaction SS as follows (Purchase et al., 2000):

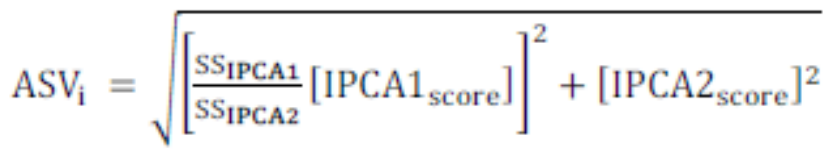

Where, $\mathrm{SS}_{\text {IPCA1 } 1} / \mathrm{SS}_{\text {IPCA2 }}$ is the weight given to the $\mathrm{IPCA}_{1}$ value by dividing the IPCA 1 sum of squares by the $\mathrm{IPCA}_{2}$ sum of squares.

Based on the rank of mean grain yield of genotypes (RYi) across environments and rank of AMMI stability value (RASVi) a selection index called Genotype Selection Index (GSI) was calculated for each genotype, which incorporates both mean grain yield (RYi) and stability index in single criteria (GSIi) as (Purchase, 2000).

\section{$\boldsymbol{G S I i}=\boldsymbol{R} A \boldsymbol{S V} \boldsymbol{i}+\boldsymbol{R} Y \boldsymbol{i}$}

Environmental index (Ii) was obtained by the difference among the mean of each environment and the general mean. Genotype plus genotype by environment variation (GGE) was used to assess the performance of genotypes in different environments. The environmental effects were removed from the data and results obtained from the data were used to calculate environment and variety scores and these scores were used to plot the standard principal component bi-plots (Yan and Kang, 2003).

Analysis of variance was carried out with a statistical analysis system (SAS) version 9.3 software (SAS Institute Inc., 2002). Additive Main Effect and Multiplicative Interaction (AMMI) analysis and GGE bi- plots were performed using Gen Stat $18^{\text {th }}$ edition statistical package (GenStat, 2016).

Table 1: Meteorological data of the test locations

\begin{tabular}{|l|l|l|l|l|l|}
\hline Locations & Altitude (masl) & Latitude & Longitude & Rain fall $(\mathrm{mm})$ & Soil type \\
\hline Bako & 1650 & $37^{\circ} 09^{\prime} \mathrm{E}$ & $09^{\circ} 06^{\prime} \mathrm{N}$ & $1431 \mathrm{~mm}$ & Sandy-clay \\
\hline Billo & 1653 & $37.09^{\prime} .15^{\prime}{ }^{\prime} \mathrm{E}$ & $0854^{\prime} 04.62^{\prime} \mathrm{N}$ & $1500 \mathrm{~mm}$ & Reddish brown \\
\hline Gute & 1915 & $\mathrm{E}: 036^{\circ} 38.196^{\prime}$ & $\mathrm{N}: 09^{\circ} 01.061^{\prime}$ & NI & Clay \\
\hline
\end{tabular}

$\mathrm{NI}=$ Not identified

\section{Results and Discussion}

\section{Combined Analysis of Variance for Individual Environments}

Analysis of variance showed statistically significant differences $(\mathrm{P}<0.01)$ among genotypes, environments and their interaction for seed yield (Table 2). This indicated the presence of genetic variation among the common bean genotypes and possibility to select high yielding and stable genotypes (s), the environments are variable and the differential response of common bean genotypes across environments. Similar result was reported for common bean and groundnut varieties, respectively by Zeleke et al. (2016) and Alemayehu et al. (2016). 
Table-2. Combined Analysis of variance for seed yield of common bean genotypes evaluated across six environments during 2015 and 2016 main cropping season.

\begin{tabular}{lcc}
\hline Source of variation & Degree freedom & Mean square \\
\hline Environments & 5 & $12668370^{* *}$ \\
Genotypes & 16 & $1993864^{* *}$ \\
Block within environments & 2 & $125429^{\text {ns }}$ \\
Interaction & 80 & $317996^{* *}$ \\
Error & 202 & 30966 \\
\hline LSD $(0.05)$ & 283.3 & \\
CV $(\%)$ & 19.9 & \\
\hline
\end{tabular}

$\mathrm{LSD}=$ Least Significant differences, $\mathrm{CV}=$ coefficient of variation, $* *=$ significant at $\mathrm{P}=0.01$, ns $=$ non-significant

The mean seed yield of large speckled common bean genotypes across environment (year $\mathrm{x}$ location) ranged from 253.7 to $1303.3 \mathrm{~kg} \mathrm{ha}^{-1}$. From all genotypes DAB-358 was the lowest yielding (Table 3). The highest grain yield was obtained from genotype DAB-361 followed by DAB-414. The average seed yield across environments ranged from the lowest of $253.7 \mathrm{~kg} \mathrm{ha}^{-1}$ for DAB-358 genotype to the highest of $1303.3 \mathrm{~kg} \mathrm{ha}^{-1}$ for DAB-361 genotype (Table 2). This difference could be due to their genetic potential. DAB-472 genotype was the top ranking genotype at two environments (Bako-2015 and Gute-2015), DAB-367 ranked first at Boshe-2015, DAB-361 at Bako-2016 and Gute-2016 (Table 2). The difference in yield rank of varieties across the environments revealed the high crossover type of GxE interaction.

Table 3. Mean seed yield and economically important diseases of of Large Speckled common bean genotypes grown across six environments in western Oromia

\begin{tabular}{|c|c|c|c|c|c|c|c|c|c|c|c|c|c|}
\hline \multirow[b]{3}{*}{ Genotype } & \multicolumn{6}{|c|}{ Seed yield $\left(\mathrm{kg} \mathrm{ha}^{-1}\right)$} & \multirow{2}{*}{\multicolumn{4}{|c|}{$\begin{array}{l}\text { CBB(1-9) Scale } \\
2015 / 16\end{array}$}} & \multirow{2}{*}{\multicolumn{3}{|c|}{$\begin{array}{l}\text { Anthracnose (1-9) Scale } \\
2015 / 16\end{array}$}} \\
\hline & 2015 & & & 2016 & & & & & & & & & \\
\hline & Bako & Boshe & Gute & Bako & Boshe & Gute & Mean & Bako & Boshe & Gute & Bako & Boshe & Gute \\
\hline DAB-446 & 1565 & 851 & 591.3 & 1180 & 941 & 535 & 943.9 & 3 & 3 & 5 & 3 & 3 & 5 \\
\hline DAB-286 & 1279 & 1171 & 78 & 736.3 & 509 & 379 & 692.1 & 3 & 2 & 4 & 4 & 4 & 5 \\
\hline DAB-443 & 1516 & 618 & 429.3 & 468.3 & 327 & 303 & 610.3 & 3 & 2 & 4 & 5 & 4 & 4 \\
\hline DAB-361 & 2650 & 693 & 573 & 1426 & 918 & 1560 & 1303.3 & 3 & 2 & 4 & 2 & 4 & 4 \\
\hline DAB-414 & 2481 & 818 & 789 & 1167.3 & 1112 & 953 & 1220.1 & 3 & 2 & 4 & 2 & 1 & 3 \\
\hline DAB-344 & 2286 & 914 & 122.3 & 941.7 & 779 & 479 & 920.3 & 3 & 2 & 4 & 3 & 2 & 2 \\
\hline DAB-341 & 2274 & 838 & 295.3 & 1092.3 & 961 & 898 & 1059.8 & 3 & 2 & 4 & 2 & 2 & 2 \\
\hline DAB-367 & 2575 & 1157 & 537.3 & 1254.7 & 728 & 560 & 1135.3 & 3 & 2 & 4 & 3 & 3 & 3 \\
\hline DAB-358 & 438 & 312 & 172.3 & 334 & 116 & 150 & 253.7 & 3 & 3 & 4 & 7 & 6 & 6 \\
\hline DAB-364 & 1782 & 573 & 732 & 1138 & 684 & 670 & 929.8 & 3 & 2 & 4 & 2 & 2 & 3 \\
\hline DAB-410 & 1944 & 991 & 89.7 & 844 & 497 & 481 & 807.8 & 3 & 2 & 4 & 3 & 3 & 5 \\
\hline DAB-337 & 1320 & 475 & 170 & 717.3 & 490 & 522 & 615.7 & 3 & 2 & 4 & 2 & 4 & 5 \\
\hline DAB-366 & 2869 & 800 & 604 & 1023.3 & 1031 & 918 & 1207.6 & 2 & 1 & 4 & 2 & 2 & 3 \\
\hline DAB-449 & 2876 & 914 & 822 & 961.7 & 810 & 798 & 1197.0 & 3 & 2 & 4 & 3 & 2 & 4 \\
\hline DAB-472 & 2931 & 891 & 1127 & 1034 & 755 & 594 & 1222.0 & 2 & 2 & 4 & 2 & 2 & 2 \\
\hline DAB-360 & 508 & 793 & 42 & 533.7 & 423 & 308 & 434.6 & 3 & 2 & 5 & 5 & 3 & 4 \\
\hline St. check & 711 & 692 & 276.3 & 425.3 & 479 & 147 & 455.1 & 3 & 2 & 4 & 6 & 3 & 5 \\
\hline $\operatorname{LSD}(0.05)$ & 450.7 & 286.9 & 361.4 & 259.4 & 280.9 & 199.1 & 113.3 & & & & & & \\
\hline $\mathrm{CV}(\%)$ & 14.3 & 21.2 & 39 & 17.3 & 24.8 & 19.8 & 22.5 & & & & & & \\
\hline
\end{tabular}

\section{AMMI Model Analysis}

The AMMI model analysis of variance for seed yield is presented in Table 4. This analysis also showed presence of highly significant $(\mathrm{p}<0.01)$ differences among common bean genotypes for seed yield performance. From the total treatment sum of squares, the largest portion was due to environments main effect (49.8\%) followed by genotypes main effect $(25.1 \%)$ and the effect of GEI was $20 \%$. The largest portion of environments sum of squares indicated greater influence of the environments on seed yield performance of common bean genotypes and contributed greater to GLI when compared to that of genotypes as main effects. Similar results were reported by Yayis, et al. (2014) and Akande, et al. (2009). Substantial percentage of G x E interaction was explained by IPCA-1 (13.7\%) followed by IPCA-2 (2.9\%) and therefore used to plot a two dimensional GGE biplot. Amare and Tamado (2014) suggested the most accurate model for AMMI can be predicted by using the first two IPCA. 
Table 4: Partitioning of the explained sum of square (SS) and mean square (MS) from AMMI analysis for seed yield of seventeen common bean genotypes

\begin{tabular}{lcccc}
\hline Source o variation & DF & Sum of square. & Explained SS (\%) & Mean square \\
\hline Total & 305 & 127189405 & 100 & 417014 \\
Treatments & 101 & 120683338 & 94.9 & $1194885^{* *}$ \\
Genotypes & 16 & 31901822 & 25.1 & $1993864^{* *}$ \\
Environments & 5 & 63341850 & 49.8 & $12668370^{* *}$ \\
Block & 12 & 1255369 & 0.98 & $104614^{* *}$ \\
Interactions & 80 & 25439666 & 20 & $317996^{* *}$ \\
IPCA 1 & 20 & 17461216 & 13.7 & $873061^{* *}$ \\
IPCA 2 & 18 & 3709783 & 2.9 & $206099^{* *}$ \\
Residuals & 42 & 4268667 & & 101635 \\
Pooled error & 192 & 5250698 & & 27347 \\
\hline
\end{tabular}

Key: ns $=$ non- significant, $* *=$ significant at $1 \%$ and $*=$ significant at $5 \%$ probability level. SS $=$ sum of square, $\mathrm{DF}=$ degree of freedom.

\section{AMMI biplots analysis}

AMMI1 biplot showed $\mathrm{G}_{3}$ (DAB-443) and $\mathrm{G}_{10}$ (DAB-364) as broadly adapted and high seed yielding. The variation of yield for each genotype was significant at different environments. Genotypes DAB-361, DAB-414, DAB-446, DAB-366, and DAB-449 were specifically adapted to high yielding environments (Fig 1). Considering the IPCA-1 score, DAB-360 was the most unstable genotype and also adapted to lower yielding environments. DAB-443 and DAB-364 were more stable in comparison to other genotypes. Genotype DAB-443 was adapted to low yielding environments and also relatively stable (Fig 1). G2 (DAB-286), G9 (DAB-358), G12 (DAB-337), G16 (DAB-360), G17 (standard check) were adapted to low yielding environments but not stable. Genotypes DAB-443 $\left(\mathrm{G}_{3}\right)$ and DAB-364 $\left(\mathrm{G}_{10}\right)$ have IPCA1 value nearest to zero by which they were shown to have a higher stability for seed yield than other genotypes (Fig 1). DAB-361 $\left(\mathrm{G}_{4}\right)$ had highest seed yield followed by DAB-472 $\left(\mathrm{G}_{15}\right)$, DAB-414 $\left(\mathrm{G}_{5}\right)$ and DAB-366 $\left(\mathrm{G}_{13}\right)$ (Fig 1).

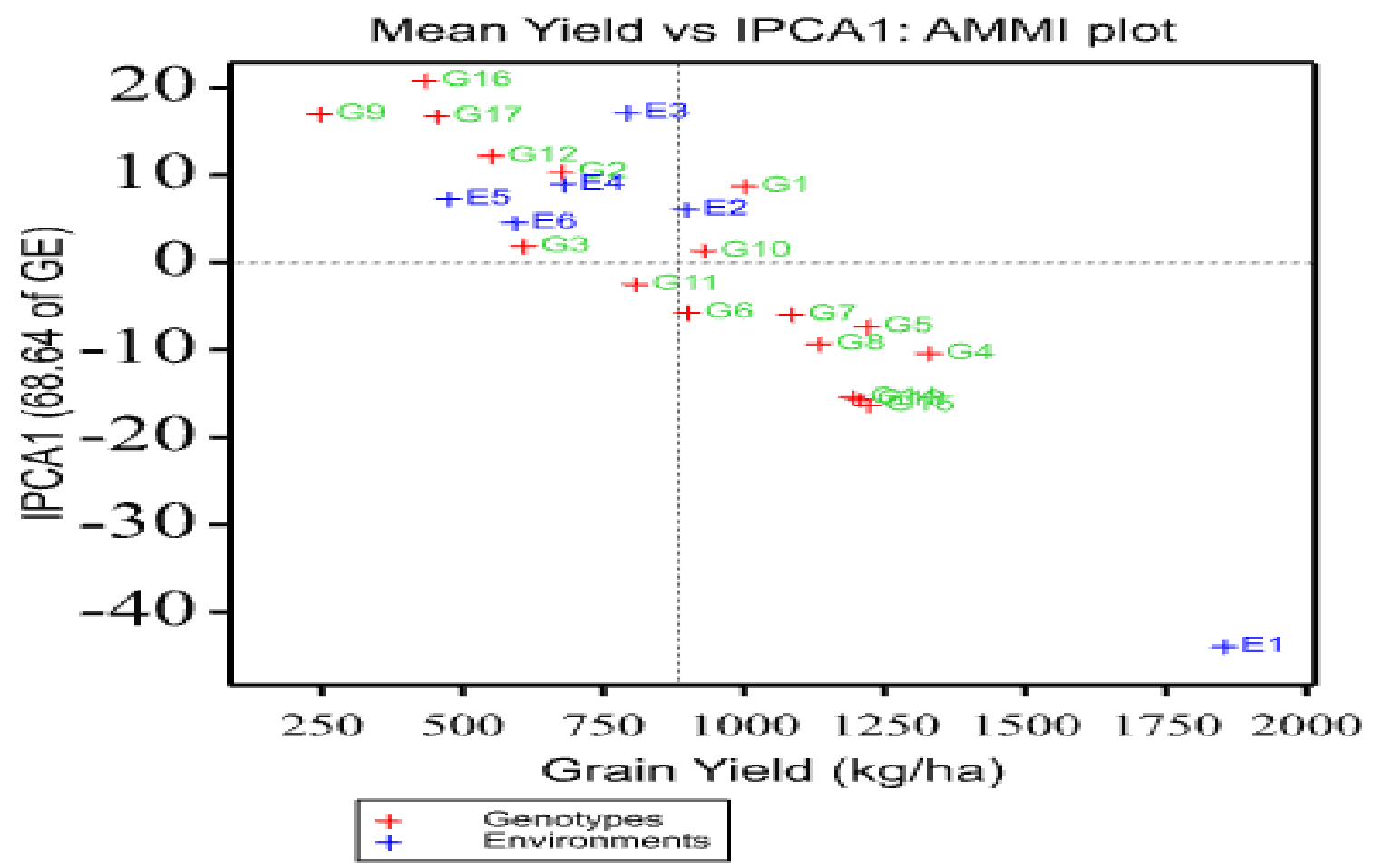

Figure- 1. Biplot of interaction principal component axis (IPCA1) against mean seed yield of 17 common bean genotypes evaluated across six environments.

AMMI stability value and genotype selection index analysis

AMMI stability value, genotype selection index values, and ranks based on them are presented in Table 3 . According to AMMI stability value (ASV), genotypes, DAB-443 and DAB-364 were found to be broadly adapted. According to GSI, genotypes, DAB-414, DAB-364 and DAB-361 with relatively lower values were found high seed yielding and broadly adapted genotypes (Table 5). 
Table 5. AMMI stability value, genotype selection index and ranks based on them for seed yield of 17 common bean genotypes evaluated at six locations during 2015 and 2016 cropping seasons.

\begin{tabular}{lccccc}
\hline Genotypes & Seed yield $\left(\mathrm{kg} \mathrm{ha}^{-1}\right)$ & ASV & RY & RASV & GSI \\
\hline DAB-446 & 1003.0 & 41.6 & 8 & 7 & 15 \\
DAB-286 & 676.6 & 51.0 & 12 & 9 & 21 \\
DAB-443 & 610.2 & 8.7 & 13 & 1 & 14 \\
DAB-361 & 1330.1 & 51.1 & 1 & 10 & 11 \\
DAB-414 & 1220.1 & 35.0 & 3 & 6 & 9 \\
DAB-344 & 901.5 & 29.1 & 10 & 5 & 15 \\
DAB-341 & 1085.7 & 28.2 & 7 & 4 & 11 \\
DAB-367 & 1135.3 & 45.3 & 6 & 8 & 14 \\
DAB-358 & 247.3 & 80.2 & 17 & 16 & 33 \\
DAB-364 & 929.9 & 12.0 & 9 & 2 & 11 \\
DAB-410 & 808.8 & 16.8 & 11 & 3 & 14 \\
DAB-337 & 552.4 & 57.6 & 14 & 11 & 25 \\
DAB-366 & 1206.7 & 74.0 & 4 & 13 & 17 \\
DAB-449 & 1194.6 & 72.6 & 5 & 12 & 17 \\
DAB-472 & 1222.2 & 76.9 & 2 & 14 & 33 \\
DAB-360 & 434.7 & 97.9 & 16 & 17 & 30 \\
Standard check & 455.1 & 78.7 & 15 & 15 & GSI:
\end{tabular}

Keys: ASV: AMMI stability value, RY: Rank of yield, RASV: Rank of AMMI stability value and GSI: Genotype selection index

\section{GGE biplot analysis}

In GGE biplot (Fig 2), IPCA-1 and IPCA-2 explained 82.28 and 7.23\%, respectively, of genotypes by environment interaction and made a total of $89.5 \%$. The other study conducted on groundnut crop explained an interaction of $85.9 \%$ extracted from IPCA-1 and IPCA-2 (Alemayehu et al., 2016). The polygon view of the GGE-biplot analysis helps one detect cross-over and non-crossover genotype-by-environment interaction and possible mega environments in multiplication yield trials (Yan et al. 2007). DAB-361 (G4), DAB-449 (G4) and DAB-358 (G9) were vertex genotypes (Fig 2). They are best in the environment lying within their respective sector in the polygon view of GGE biplot (Yan and Tinker, 2006).

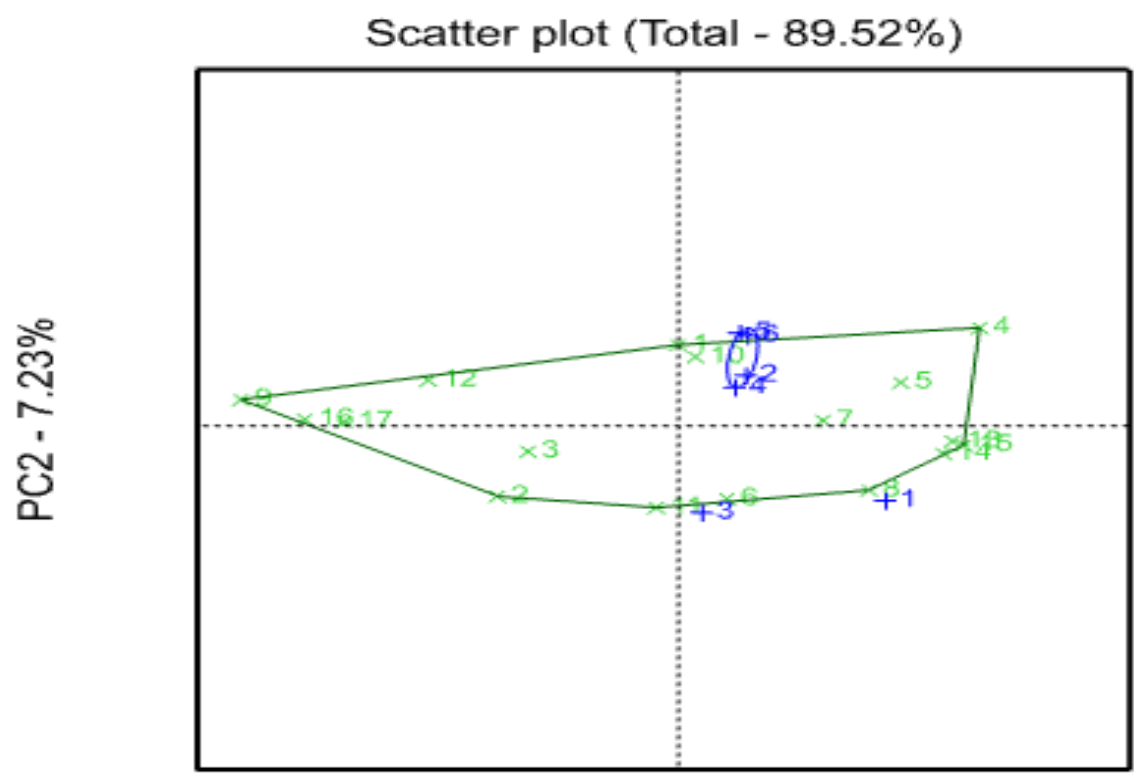

PC1 - 82.28\%

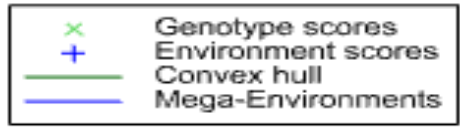

Fig- 2. GGE biplot showing mega-locations and their respective higher seed yielding genotypes. Varieties plotted as $1,2 \ldots 17$. Locations are those written in blue color. 


\section{Conclusion}

GEI is differential phenotypic performance of genetically uniform genotypes across test environments. It occurs because different genotypes have different genetic potentials to adjust themselves to variable environments, that is, adaptability. Large speckled common bean genotypes evaluated have highly significant genetic differences for seed yield performance and occurrence of significant GEI complicated selection of high yielding and broadly adapted genotypes. GGE biplot enabled identification of both high seed yielding and broadly adapted genotypes better than AMMI biplot, ASV and GSI. Among the evaluated genotypes DAB-361 (G4) was both high seed yielding and broadly adapted genotype. Locations, Bako 2015 and Bako 2016 are high seed yield potential locations and ideal for commercial production of common bean genotypes broadly adapted to them. GGE biplot analysis suggested presence of one mega-environments and enabled identification of specifically adapted genotypes.

\section{References}

Adjei, A.I., S.O. Dapaah and I.K. Dontwi, 2010. Predicting the best genotype from analysis of genotype by environment interaction. European J. Sci. Res., 45(1): 128-135.

Akande, S. R., Taiwo, L. B., Adegbite, A. A., and Owolade, O. F., 2009. "Genotype x environment interaction for soybean grain yield and other reproductive characters in the forest and savanna agroecologies of Southwest Nigeria." African Journal of Plant Science, vol. 3, pp. 127-132.

Alemayehu Dabessa, Birru Alemu, Zerihun Abebe and Dagnachew Lule. 2016. Genotype by Environment Interaction and Kernel Yield Stability of Groundnut (Arachis hypogaea L.) Varieties in Western Oromia, Ethiopia. Journal of Agriculture and Crops, 2(11): 113-120.

CSA (Central Statistical Agency). 2016. Agricultural Sample Survey Report on Area and Production of Major Crops, 1: 21-22.

Ebdon, J. S, H.G Gauch, 2002b. Additive main effect and multiplicative interaction analysis of national turfgrass performance trials II: Cultivar recommendations. Crop Sci. 42: 497-506.

Gauch, H.G., and R. W. Zobel, 1997. Identifying mega-environments and targeting genotypes. Crop Sci. 37: 11326.

GenStat, 2016. GenStat Procedure Library Release. $18^{\text {th }}$ edition. VSN International Ltd.

Liebenberg, J. A., 2002. Dry bean production. Dry bean production manual compiled by Directorate Agricultural information services Department of Agriculture in cooperation with ARC, Seed Crops Institute, SouthAfrica. (Available athttp://www.ndg.agric.za/publications(Accessed July 2010)

Mekbib, F., 2003. Yield stability in common bean (Phaseolus vulgaris L.) genotypes. Euph. 130: 147-153.

Purchase, J.L., H. Hatting and Cs.Vandenventer, 2000. Genotype by environments interaction of wheat in South Africa: stability analysis of yield performance. South Africa J. of plant sci. 17: 101-107.

Yan W., Tinker N.A. 2006. Biplot analysis of multi-environment trial data: Principles and applications. Canadian Journal of Plant Science 86, 623-645.

Yan, W., and Kang, M.S. 2003. GGE Biplot Analysis: a Graphical Tool for Breeders, Geneticists and Agronomists. CRC Press, Boca Raton.

Yayis, R., Agdew, B., and Yasin, G., 2014. "Genotype x environment interaction and Additive main effect and multiplicative interaction analysis for Field pea yield stability in SNNPR state, Ethiopia." International Journal of Sustainable Agricultural Research, vol. 1, pp. 28-38.

Zeleke Ashango, Berhanu Amsalu, Kidane Tumisa, Kassaye Negash and Asnake Fikre. 2016. Seed Yield Stability and Genotype x Environment Interaction of Common Bean (Phaseolus vulgaris L.) Lines in Ethiopia. International Journal of Plant Breeding and Crop Science, 3(2): 135-144.

Amare Kebede* and Tamado Tana., 2014. Genotype by Environment Interaction and Stability of Pod Yield of Elite Breeding Lines of Groundnut (Arachis hypogaea L.) in Eastern Ethiopia. Science and Technol. Arts Research. Journal. April-June 2014, 3(2): 43-46

Gauch, H.G., Jr., and R.W. Zobel. 1997. Identifying mega-environments and targeting genotypes. Crop Sci. $37: 311-326$ 